\title{
Angiotensin-Converting Enzyme 2 Improves Arterial Hypoxemia in Meconium-Induced Acute Lung Injury in Piglets
}

\author{
Benedikt Treml, ${ }^{1}$ Alexander Loeckinger, ${ }^{2}$ Axel Kleinsasser, ${ }^{1}$ Elisabeth Schoepf, \\ Ralf Geiger, ${ }^{3}$ and Nikolaus $\mathrm{Neu}^{4}$ \\ ${ }^{1}$ Department of Anesthesiology and CCM, Innsbruck Medical University, 6020 Innsbruck, Austria \\ ${ }^{2}$ Department of Anesthesiology and CCM, Hanusch Krankenhaus, 1140 Vienna, Austria \\ ${ }^{3}$ Department of Pediatrics, Hospital Bruneck, 39031 Bruneck, Italy \\ ${ }^{4}$ Pediatric Intensive Care Unit, Department of Pediatrics, Innsbruck Medical University, 6020 Innsbruck, Austria
}

Correspondence should be addressed to Nikolaus Neu; nikolaus.neu@i-med.ac.at

Received 20 October 2014; Revised 4 January 2015; Accepted 20 January 2015

Academic Editor: An Massaro

Copyright (C) 2015 Benedikt Treml et al. This is an open access article distributed under the Creative Commons Attribution License, which permits unrestricted use, distribution, and reproduction in any medium, provided the original work is properly cited.

\begin{abstract}
Objective. Meconium aspiration induces acute lung injury (ALI) in neonates born through meconium-stained amniotic fluid. As yet, there is no specific therapy for improving the outcome. Recently, angiotensin-converting enzyme 2 (ACE2), which inactivates angiotensin II (Ang II), has been shown to ameliorate murine ALI. Design. To evaluate the therapeutic potential of this substance, we studied ACE2 in a piglet model of ALI induced by meconium aspiration. Subjects. Twelve anesthetized piglets were subjected in an animal research laboratory. ALI was induced by tracheal meconium instillation. Thereafter, six animals were randomly assigned to the ACE2 group, while another 6 served as control. Measurements. Systemic, pulmonary hemodynamic, and blood gas exchange parameters and Ang II levels were examined before ALI induction and at various time points after administering ACE2 or saline. In addition, ventilation-perfusion distribution of the lung was assessed by the multiple inert gas elimination technique (MIGET). Main Results. Animals treated with ACE2 maintained significantly higher arterial partial pressures of oxygen $\left(\mathrm{PaO}_{2}\right)$ and lower arterial partial pressures of carbon dioxide $\left(\mathrm{Paco}_{2}\right)$, respectively. Furthermore, Ang II, which was substantially increased, returned to basal values. Conclusion. In summary, ACE2 improves blood gas exchange in meconium-induced ALI in piglets.
\end{abstract}

\section{Introduction}

In neonates, aspiration of meconium causes acute lung injury (ALI) and may lead to severe acute respiratory distress syndrome (ARDS), often associated with persistent fetal circulation $[1,2]$. Death occurs in about $10 \%$ of the cases [3]. Similar to the situation in adults, neonates with ARDS require supportive intensive care including aggressive mechanical ventilation, circulatory support by catecholamines, and, in most severe cases, extracorporeal membrane oxygenation.

Recently, angiotensin-converting enzyme 2 (ACE2) has been described as a new principal enzyme of the renin-angiotensin-aldosterone system [4, 5]. Angiotensin II (Ang II), a product of ACE, is cleaved by ACE2 generating vasodilator mediators [4-6]. Experimental data indicate an important role of ACE2 in the development of ARDS. For instance,
ACE2 protects wild type mice from severe lung injury induced by acid aspiration, colon ligation, or endotoxin shock, and ACE2-knockout mice are more susceptible to these forms of lung disease as compared to wild type animals [7]. Furthermore, we recently showed that ACE2 ameliorates failure of oxygenation in a piglet model of lung injury induced by lipopolysaccharide (LPS) [8].

In our study, we investigated the potential influence of ACE2 on respiratory and hemodynamic parameters in a piglet model following meconium aspiration. This model is particularly suitable, because it allows the assessment of exactly the same parameters that are required for the monitoring of the disease in human intensive care medicine. Furthermore, this model allows the application of the multiple inert gas elimination technique (MIGET) [9-11] to assess ventilation/perfusion distribution in the lung tissue. 


\section{Material and Methods}

2.1. Subjects. All experiments were approved by the Austrian Federal Animal Investigational Committee. Twelve healthy, eight-week-old crossbreed piglets (German landrace $\mathrm{x}$ Pietrain) of either sex were selected from a local stock regularly used for experimental research. Prior to induction of anesthesia the animals received ketamine (50 mg/ $\mathrm{kg}$ i.m.) and atropine $(0.01 \mathrm{mg} / \mathrm{kg}$ i.v.). Following endotracheal intubation, anaesthesia was maintained with i.v. propofol (10$15 \mathrm{mg} / \mathrm{kg} / \mathrm{h}$; Perfusor Secura FT, B. Braun Melsungen AG, Melsungen, Germany) and boluses of $15 \mathrm{mg}$ piritramide. All pigs were mechanically ventilated in volume-controlled mode (Evita 2, Drägerwerk AG \& Co. KGaA, Lübeck, Germany) at an inspiratory fraction of oxygen $\left(\mathrm{FiO}_{2}\right)$ of 0.21 and a tidal volume (VT) of $10 \mathrm{~mL} / \mathrm{kg}$ at $15 \mathrm{breaths} / \mathrm{min}$, positive end expiratory pressure set at $5 \mathrm{mmHg}$. Throughout the procedure, Ringer's solution $(6 \mathrm{~mL} / \mathrm{kg} / \mathrm{h})$ and a $3 \%$ gelatin solution $(4 \mathrm{~mL} / \mathrm{kg} / \mathrm{h})$ were infused. A standard lead II ECG (Datex Ohmeda AS/3, Datex-Ohmeda Inc., Wisconsin, USA) was used to monitor cardiac rhythm. Body temperature was maintained between $38^{\circ} \mathrm{C}$ and $39^{\circ} \mathrm{C}$ by using an electric heating blanket (Warm Air Model 134, Cincinnati Sub-Zero Inc., Ohio, USA). A $8.5 \mathrm{~F}$ pulmonary artery catheter (131HF7, Edwards Lifesciences, California, USA) was advanced from the internal jugular vein into a branch of the pulmonary artery to measure mean pulmonary arterial pressure (MPAP), pulmonary capillary wedge pressure (PCWP), central venous pressure (CVP), and cardiac output using the thermodilution technique $(10 \mathrm{~mL}$ saline in triplicate) and to obtain mixed venous blood. A 6 F arterial catheter (SI-09600, Arrow International Inc., Pennsylvania, USA) introduced into the femoral artery was used to monitor systemic blood pressure and to take blood samples for blood gas and MIGET analyses. All catheters were filled with saline and connected to pressure transducers zeroed to ambient pressure at the level of the right atrium. Pulmonary vascular resistance (PVR) was calculated using standard formulas.

2.2. Experimental ARDS Protocol. After surgical preparations, all animals were moved into prone position and left for stabilization for $30 \mathrm{~min}$. Thereafter, baseline measurements (i.e., "0 min") including hemodynamics, blood gases, ventilation, and MIGET were taken. As a next step, acute lung injury was induced using deep intratracheal instillation of a $20 \%$ solution of pooled human meconium. First, all piglets received $0.5 \mathrm{~mL} / \mathrm{kg}$ of meconium solution over a period of $3 \mathrm{~min}$, and $\mathrm{FiO}_{2}$ was set to 1.0 to counteract effects of acute hypoxia like pulmonary hypertension and acute right heart failure. After $3 \mathrm{~min}$, boluses of $0.25 \mathrm{~mL} / \mathrm{kg}$ meconium were titrated up to a maximum of $2.0 \mathrm{~mL} / \mathrm{kg}$. Meconium instillation was stopped after MPAP increased to values 50 percent above baseline and $\mathrm{FiO}_{2}$ was set to 0.21 . Both groups received approximately the same amount of meconium (data not shown). Thereafter, respirator settings were not changed for the remaining course of the experiment.

Thirty minutes after meconium instillation, all animals were randomly assigned to two groups. In accordance with previous murine (7) and porcine (8) ARDS-models, one group $(n=6)$ received $400 \mu \mathrm{g} / \mathrm{kg}$ ACE2 intravenously, whereas controls $(n=6)$ received saline only.

Every $30 \mathrm{~min}$, measurements were obtained including hemodynamics, ventilation, and blood gas parameters. MIGET was performed at 0, 30, 60, 120, 180, and $240 \mathrm{~min}$. Ang II and ACE2 levels in plasma and serum, respectively, were measured at $0,30,60,120,180$, and $240 \mathrm{~min}$. Plasma and serum samples were supplemented with a protease inhibitor cocktail (phenanthroline, pepstatin A, p-hydroxymercuribenzoic acid, and EDTA) and were stored frozen at $-20^{\circ} \mathrm{C}$ until analysis. After $270 \mathrm{~min}$, all piglets were euthanized by i.v. injection of $20 \mathrm{~mL} 1 \mathrm{M}$ potassium chloride. The heart was removed and inspected to rule out any anatomical abnormalities. MIGET was performed as previously described $[9,10]$. Six inert gases, prepared in sterile $0.9 \%$ sodium chloride solution, were continuously i.v. infused at a rate of $3 \mathrm{~mL} / \mathrm{min}$. Samples of expired gas and arterial and mixed venous blood were obtained in gas-tight glass syringes. The concentrations of the six inert gases in expired air and arterial and mixed venous blood were measured using a gas chromatograph (Hewlett-Packard 5890, series II). $V_{A} / Q$ distribution reflects regional lung ventilation/perfusion, including lung units ranging from either shunt (i.e., unventilated lung units) or dead space ventilation (i.e., lung units without blood flow). $V_{A} / Q$ was calculated using least squares best fit regression analysis. In the MIGET, adequacy of fit of the data to the model is assessed by the remaining sum of squares (RSS). RSS was $\geq 10.6$ in $92.6 \%$ of all MIGET analysis, thereby indicating good data quality.

2.3. Histopathology. For histological analyses, lung tissue samples were fixed in $10 \%$ formalin. After embedding in paraffin, sections were obtained and stained with haematoxylin and eosin ( $\mathrm{H} \& \mathrm{E})$ according to standard methods. Lung tissue sections were scored by two pathologists blinded to treatment.

2.4. Preparation of Human Meconium. Pooled human meconium was suspended in physiological saline at a concentration of $20 \%$ and stored at $-20^{\circ} \mathrm{C}$ until use.

2.5. ACE2 Preparation and Measurement of ACE2 and Ang II in Plasma. The preparation of recombinant ACE2 and the measurements of ACE2 activity and Ang II levels in plasma samples were performed as previously described [8].

2.6. Statistical Analysis. A two-way ANOVA was used to determine inter- and intragroup differences. Significant results were post hoc analyzed using the Newman-Keuls and Fisher's exact tests and the unpaired $t$-test. Results are given as mean $\pm \mathrm{SD}$ (standard deviation). Values of $P \leq 0.05$ were considered significant.

\section{Results}

ALI was induced in 12 animals by meconium instillation. After 30 min, 6 animals received recombinant soluble ACE2, whereas 6 animals where sham-treated with saline. 


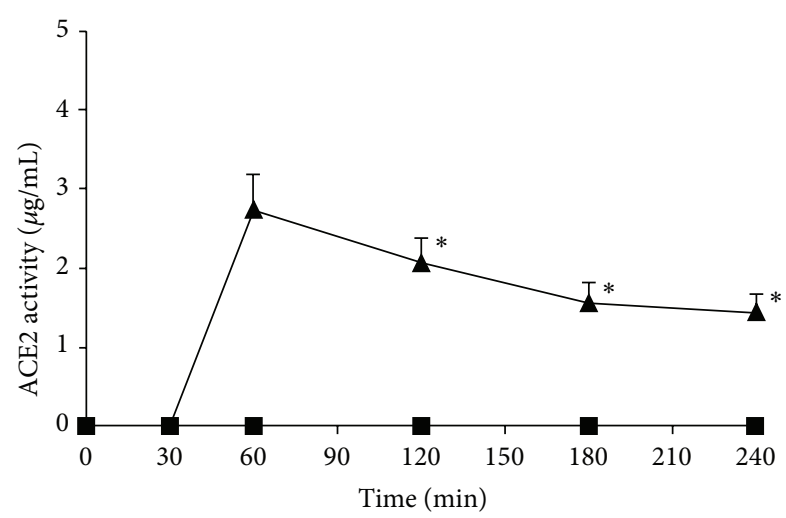

FIGURE 1: ACE2 levels in meconium treated animals receiving rhACE2 (recombinant humane angiotensin-converting enzyme 2, $\boldsymbol{\Delta}, n=6)$ or saline $(\boldsymbol{\square}, n=6) .20 \%$ meconium solution was instillated at $0 \mathrm{~min}$, followed by a single bolus injection of $400 \mu \mathrm{g} / \mathrm{kg} \mathrm{rhACE} 2$ or saline at 30 min. ${ }^{*} P<0.05$ versus controls. Values are mean \pm SEM.

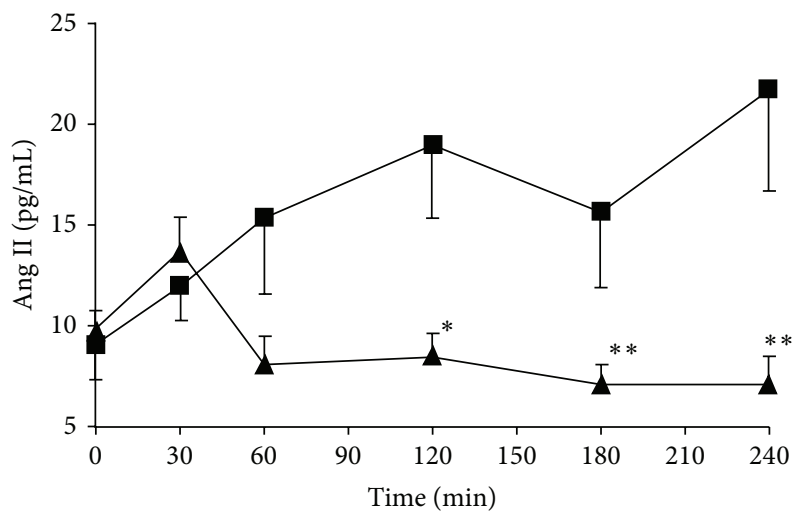

FIGURE 2: Ang II levels in meconium treated animals receiving rhACE2 (recombinant humane angiotensin-converting enzyme 2, $\mathbf{\Delta}, n=6)$ or saline $(\boldsymbol{\square}, n=6) .20 \%$ meconium solution was instillated at $0 \mathrm{~min}$, followed by a single bolus injection of $400 \mu \mathrm{g} / \mathrm{kg}$ rhACE2 or saline at 30 min. ${ }^{*} P<0.05$ versus controls. ${ }^{* *} P<0.05$ versus controls. Values are mean \pm SEM.

3.1. ACE2 Treatment Reduces Systemic Ang II Levels in Acute Lung Injury. Prior to meconium instillation, no (intrinsic) ACE2 activity could be found in the sera of piglets (Figure 1).

Basal Ang II levels were similar in both groups. Meconium instillation induced a nearly 35 percent increase of Ang II after $30 \mathrm{~min}$ in both groups (Figure 2). In controls, Ang II further increased to a 3-fold level at the end of the observation period. ACE2, however, decreased Ang II below baseline values immediately after application, remaining at this level until the end of the experiment.

3.2. Changes in Blood Gases and Hemodynamics. Immediately after meconium instillation, $\mathrm{PaO}_{2}$ substantially decreased (Figure 3(a)). In parallel, the alveoloarterial partial pressure difference of oxygen $\left(\mathrm{AaDO}_{2}\right)$ increased (Table 1). Furthermore, $\mathrm{PaCO}_{2}$ increased (Figure 3(b)), as did the mixed venous partial pressure of carbon dioxide $\left(\mathrm{PvcO}_{2}\right)$ (Table 1). Mixed venous partial pressure of oxygen $\left(\mathrm{Pvo}_{2}\right)$ decreased. Also, mean arterial pressure (MAP) decreased shortly after meconium instillation, and MPAP increased by approximately one-third. PVR nearly doubled 30 min after meconium and further increased until the end of the experiment (Table 1).

In controls, $\mathrm{PaO}_{2}$ remained decreased but increased in the ACE2 group immediately after treatment and remained at this level (Figure 3(a)). $\mathrm{PacO}_{2}$ constantly increased in controls but decreased in the ACE2 group (Figure 3(b)). $\mathrm{PvCO}_{2}$ behaved in a similar manner (Table 1).

MAP in controls remained nearly unchanged, but ACE2 animals showed higher MAP levels after 180 and $240 \mathrm{~min}$ (Table 1).

Heart rate increased in both groups during the course of the experiment. All other hemodynamic and blood gas parameters, that is, PCWP, CVD, and the arterial $\mathrm{pH}(\mathrm{pHa})$, remained unchanged at all time points tested, regardless of whether the animals received ACE2 or saline (Table 1).

3.3. Changes in Ventilation-Perfusion Distribution. Meconium led to an impairment of pulmonary blood flow as expressed by an increased LogSDQ (Table 2). This expression, the logarithmic standard deviation of perfusion distribution, describes the homogeneity of pulmonary blood flow. Furthermore, blood flow to unventilated lung units (i.e., shunt) increased, while blood flow to normally ventilated units (normal $V_{A} / Q$ of $Q$ ) decreased (Table 2). ACE2 administration did not change any of these MIGET parameters in a significant manner. Differences in shunt fraction and $\mathrm{pH}$, immediately before and subsequent to ACE2-infusion, might have resulted from uneven response to meconium between individual animals. Therefore, the lack of significance might in part be due to the small sample size.

3.4. Changes in Lung Histology. The histologic picture of meconium-induced ALI was characterized by extensive collapse of the alveolar system due to bronchiolar obstruction by meconium (Figure 4(a)). ACE2 did not alter the histopathologic pattern (not shown).

\section{Discussion}

The present study demonstrates that ACE2 ameliorates meconium-induced ALI in piglets by attenuating pulmonary gas exchange, that is, by increasing $\mathrm{PaO}_{2}$ and decreasing $\mathrm{PaCO}_{2}$.

Meconium induces expression of inflammatory cytokines and Ang II-mediated apoptotic processes in human and animal alveolar epithelial cells [12]. In our model, meconium led to a substantial increase of Ang II, most probably by hyperactivity of ACE [13, 14]. Ang II binds to the Ang II subtype la (ATla) receptor of the lung microvascular endothelium, resulting in edema and inflammation [7]. Rosenfeld et al. showed that meconium leads to a 3-fold increase of total lung AT1 receptor protein and induces AT1 receptor-mediated apoptotic cell death in the newborn rabbit lung [15]. Thus, Ang II seems to be an important mediator of acute lung injury induced by meconium aspiration. In 


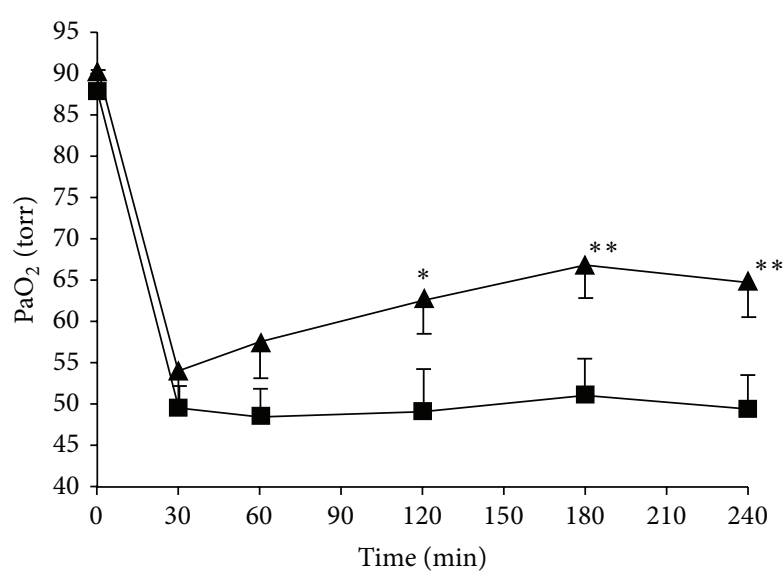

(a)

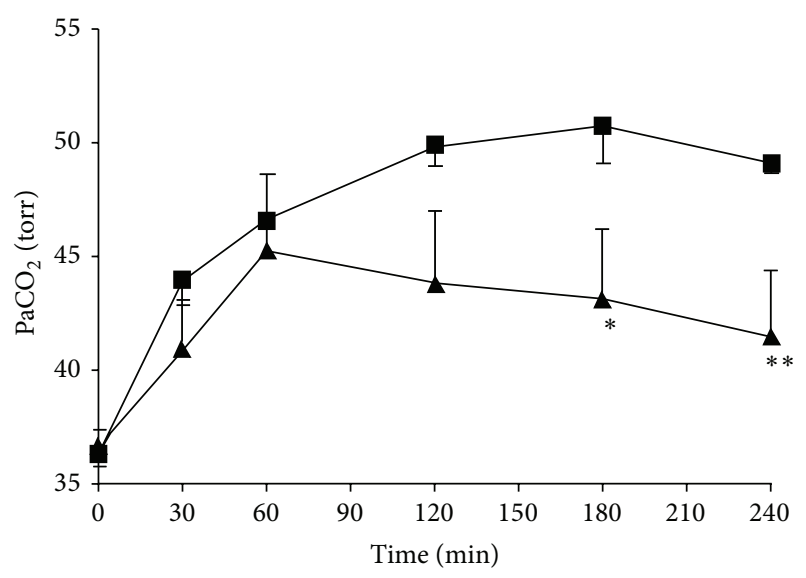

(b)

FIgURE 3: (a) $\mathrm{PaO}_{2}$ levels in meconium treated animals receiving rhACE2 (recombinant humane angiotensin-converting enzyme 2, $\mathbf{\Lambda}, n=6$ ) or saline $(\mathbf{\square}, n=6) .20 \%$ meconium solution was instillated at $0 \mathrm{~min}$, followed by a single bolus injection of $400 \mu \mathrm{g} / \mathrm{kg} \mathrm{rhACE} 2 \mathrm{or}$ saline at 30 min. ${ }^{*} P<0.05$ versus control. ${ }^{* *} P<0.01$ versus control. Values are mean \pm SEM. (b) $\mathrm{Paco}_{2}$ levels in meconium treated animals receiving rhACE2 (recombinant humane angiotensin-converting enzyme 2, $\mathbf{\Delta}, n=6)$ or saline $(\mathbf{\square}, n=6)$. 20\% meconium solution was instillated at $0 \mathrm{~min}$, followed by a single bolus injection of $400 \mu \mathrm{g} / \mathrm{kg}$ rhACE2 or saline at $30 \mathrm{~min} .{ }^{*} \mathrm{P}<0.05$ versus control. ${ }^{* *} P<0.01$ versus control. Values are mean \pm SEM.

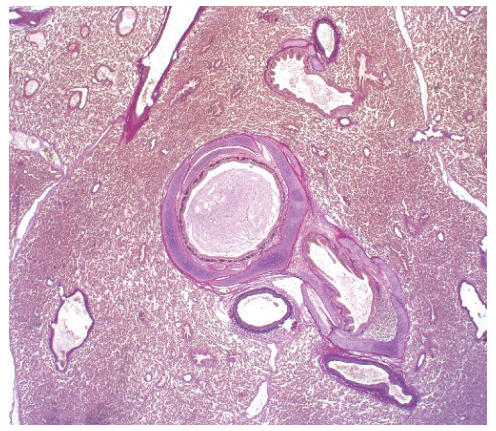

(a)

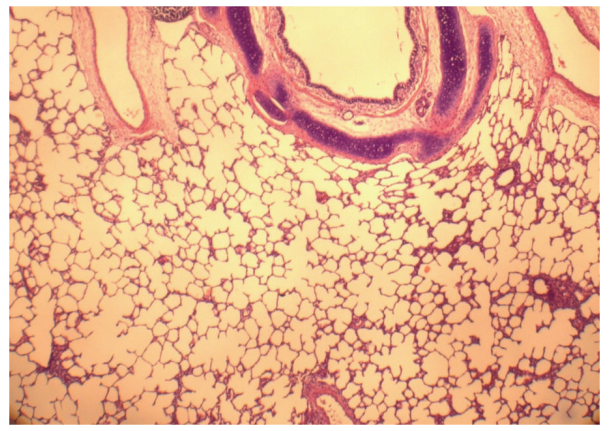

(b)

FIGURE 4: (a) Lung tissue from a piglet after meconium instillation showing atelectases and complete collapse of the alveoli (hematoxylineosin staining; $\times 200$ ). (b) Normal lung tissue from an untreated animal showing regular architecture of the alveolar system.

agreement with our previous work in LPS-induced ARDS, ACE2 inactivates Ang II by cleavage to angiotensin 1-7 (AT 1-7) in vivo [8]. Furthermore, AT 1-7 acts as an endogenous antagonist of Ang II and has recently been shown to prevent murine ventilator- or acid aspiration-induced ALI [16]. AT 17 binds to the MAS receptor, and, in turn, administration of a MAS-inhibitor aggravates lung fibrosis [17]. Altogether, these observations might provide the pharmacological basis for the mechanism by which ACE2 attenuates meconium-induced ALI.

Meconium instillation increased MPAP to $135 \%$ of baseline, and this value remained unchanged after ACE2 treatment. This is in contrast to the previously described LPSARDS model, where MPAP increased 2-fold and slightly dropped after ACE2. A lesser increase of Ang II levels after meconium instillation compared to LPS (35\% versus 8 -fold in the LPS model) could explain this difference. However, administration of ACE2 was followed by a return to basal Ang II values in both models.
One probable but unwanted side effect of ACE2 administration could be a drop in blood pressure. However, after 180 min, MAP even increased in the ACE2 group despite decreased Ang II levels. This might be important for clinical testing, as meconium aspiration often is associated with severe hypotension requiring catecholamines.

Apart from our experimental setting, well-established substances like the ACE inhibitor captopril and the angiotensin II receptor antagonist telmisartan also have been tested in experimental ALI. For example, captopril has been shown to attenuate ALI in rats [18] and Liu and Guo observed decreased TNF- $\alpha$ levels and an increased $\mathrm{PaO} 2$ after captopril in rats subjected to hydrochloric acid-induced ALI [19]. In meconium- or LPS-treated piglets, lisinopril or telmisartan led to severe hemodynamic instability requiring high doses of catecholamines. This rescue treatment, however, significantly impaired the accuracy of MIGET (unpublished observations). 
TABLE 1: Hemodynamic and blood gas measurements.

\begin{tabular}{|c|c|c|c|c|c|c|}
\hline & $0 \mathrm{~min}$ & $30 \mathrm{~min}$ & $60 \mathrm{~min}$ & $120 \mathrm{~min}$ & $180 \mathrm{~min}$ & $240 \mathrm{~min}$ \\
\hline \multicolumn{7}{|l|}{ HR } \\
\hline $\operatorname{rhACE} 2(n=6)$ & $102 \pm 12$ & $104 \pm 19$ & $108 \pm 19$ & $101 \pm 11$ & $112 \pm 19$ & $112 \pm 22$ \\
\hline Control $(n=6)$ & $100 \pm 10$ & $103 \pm 19$ & $107 \pm 13$ & $111 \pm 12$ & $117 \pm 11$ & $118 \pm 10$ \\
\hline \multicolumn{7}{|l|}{ MAP } \\
\hline $\operatorname{rhACE} 2(n=6)$ & $96 \pm 7$ & $93 \pm 11$ & $103 \pm 9$ & $111 \pm 10$ & $108 \pm 12^{\mathrm{a}}$ & $105 \pm 13^{b}$ \\
\hline Control $(n=6)$ & $89 \pm 9$ & $86 \pm 8$ & $89 \pm 9$ & $99 \pm 14$ & $88 \pm 9$ & $84 \pm 18$ \\
\hline \multicolumn{7}{|l|}{ MPAP } \\
\hline $\operatorname{rhACE} 2(n=6)$ & $23 \pm 1$ & $31 \pm 3$ & $31 \pm 4$ & $33 \pm 3$ & $33 \pm 5$ & $31 \pm 5$ \\
\hline Control $(n=6)$ & $23 \pm 1$ & $31 \pm 3$ & $33 \pm 4$ & $34 \pm 3$ & $33 \pm 2$ & $33 \pm 2$ \\
\hline \multicolumn{7}{|l|}{ PCWP } \\
\hline $\operatorname{rhACE} 2(n=6)$ & $12 \pm 1$ & $12 \pm 1$ & $12 \pm 1$ & $11 \pm 1$ & $12 \pm 1$ & $12 \pm 1$ \\
\hline Control $(n=6)$ & $11 \pm 1$ & $11 \pm 3$ & $11 \pm 3$ & $11 \pm 3$ & $11 \pm 3$ & $11 \pm 3$ \\
\hline \multicolumn{7}{|l|}{$\mathrm{CO}$} \\
\hline $\operatorname{rhACE} 2(n=6)$ & $5.1 \pm 0.5$ & $4.8 \pm 0.5$ & $4.8 \pm 0.6$ & $4.4 \pm 0.8$ & $4.7 \pm 0.8$ & $4.3 \pm 0.6$ \\
\hline Control $(n=6)$ & $4.2 \pm 0.5$ & $4.0 \pm 0.8$ & $4.0 \pm 0.6$ & $3.8 \pm 0.4$ & $4.0 \pm 0.8$ & $3.6 \pm 0.4$ \\
\hline \multicolumn{7}{|l|}{ PVR } \\
\hline $\operatorname{rhACE} 2(n=6)$ & $171 \pm 18$ & $309 \pm 17$ & $299 \pm 16$ & $398 \pm 41$ & $375 \pm 57$ & $358 \pm 50$ \\
\hline Control $(n=6)$ & $234 \pm 18$ & $429 \pm 58$ & $435 \pm 42$ & $468 \pm 34$ & $473 \pm 64$ & $498 \pm 56$ \\
\hline \multicolumn{7}{|l|}{ CVP } \\
\hline rhACE2 $(n=6)$ & $8 \pm 1$ & $9 \pm 1$ & $8 \pm 1$ & $9 \pm 1$ & $8 \pm 2$ & $7 \pm 1$ \\
\hline Control $(n=6)$ & $8 \pm 2$ & $9 \pm 2$ & $9 \pm 2$ & $9 \pm 2$ & $9 \pm 1$ & $9 \pm 2$ \\
\hline \multicolumn{7}{|l|}{$\mathrm{pHa}$} \\
\hline $\operatorname{rhACE} 2(n=6)$ & $7.49 \pm 0.05$ & $7.45 \pm 0.06$ & $7.42 \pm 0.07$ & $7.42 \pm 0.06$ & $7.42 \pm 0.06$ & $7.43 \pm 0.06$ \\
\hline Control $(n=6)$ & $7.44 \pm 0.05$ & $7.38 \pm 0.05$ & $7.35 \pm 0.05$ & $7.34 \pm 0.04$ & $7.35 \pm 0.04$ & $7.34 \pm 0.04$ \\
\hline \multicolumn{7}{|l|}{$\mathrm{Pvo}_{2}$} \\
\hline $\operatorname{rhACE} 2(n=6)$ & $38 \pm 2$ & $32 \pm 3$ & $32 \pm 4$ & $34 \pm 1$ & $34 \pm 2$ & $30 \pm 3$ \\
\hline Control $(n=6)$ & $40 \pm 4$ & $29 \pm 3$ & $29 \pm 4$ & $28 \pm 7$ & $30 \pm 4$ & $27 \pm 6$ \\
\hline \multicolumn{7}{|l|}{$\mathrm{PvcO}_{2}$} \\
\hline rhACE2 $(n=6)$ & $40 \pm 3$ & $44 \pm 3$ & $47 \pm 7$ & $48 \pm 7$ & $47 \pm 8^{\mathrm{b}}$ & $46 \pm 7^{\mathrm{b}}$ \\
\hline Control $(n=6)$ & $40 \pm 2$ & $46 \pm 2$ & $50 \pm 5$ & $53 \pm 4$ & $55 \pm 4$ & $56 \pm 3$ \\
\hline \multicolumn{7}{|l|}{$\mathrm{AaDo}_{2}$} \\
\hline $\operatorname{rhACE} 2(n=6)$ & $12 \pm 4$ & $44 \pm 7$ & $37 \pm 10$ & $31 \pm 6$ & $32 \pm 4$ & $35 \pm 9$ \\
\hline Control $(n=6)$ & $11 \pm 7$ & $47 \pm 8$ & $44 \pm 7$ & $39 \pm 11$ & $36 \pm 7$ & $42 \pm 14$ \\
\hline
\end{tabular}

rhACE2: recombinant humane angiotensin-converting enzyme 2; HR: heart rate (1/min); MAP: mean arterial blood pressure (mmHg); MPAP: mean pulmonary arterial blood pressure (mmHg); PCWP: pulmonary capillary wedge pressure (mmHg); CO: cardiac output (L/min); PVR: pulmonary vascular resistance $\left(\right.$ dyne $\left.* \mathrm{~s} / \mathrm{cm}^{5}\right) ; \mathrm{CVP}$ : central venous pressure $(\mathrm{mmHg}) ; \mathrm{pHa}$ : arterial $\mathrm{pH} ; \mathrm{Pvo}_{2}$ : mixed venous partial pressure of oxygen (torr); $\mathrm{PvcO}_{2}$ : mixed venous partial pressure of carbon dioxide (torr); $\mathrm{AaDo}_{2}$ : alveoloarterial partial pressure difference of oxygen (torr). ${ }^{\mathrm{a}} \mathrm{P}<0.05$ compared to controls. ${ }^{\mathrm{b}} P<0.01$ compared to controls. Values are mean \pm SD.

A possible limitation of our study is the observation period of $240 \mathrm{~min}$, as a longer time course of meconium aspiration could have led to more pronounced effects in hemodynamics and blood gas measurements. Also, for technical reasons the lung weights have not been measured.

We hypothesized that ACE2 inactivated Ang II by cleavage to AT 1-7. Studies are now under way to evaluate the therapeutic potential of both ACE2 and AT 1-7 in a clinical setting.

\section{Conclusion}

We investigated the therapeutic potential of ACE2 administration on meconium-induced acute lung injury in a piglet model. ACE2 attenuates arterial hypoxemia and hypercapnia. Accordingly, this substance seems to improve pulmonary gas exchange.

\section{Abbreviations}

ALI: Acute lung injury

ARDS: Acute respiratory distress syndrome

$\mathrm{AaDO}_{2}:$ Alveoloarterial partial pressure difference of oxygen

ACE: Angiotensin-converting enzyme

ACE2: Angiotensin-converting enzyme 2

AT 1-7: Angiotensin 1-7

Ang II: Angiotensin II 
TABLE 2: Inert gas data.

\begin{tabular}{|c|c|c|c|c|c|c|}
\hline & $0 \mathrm{~min}$ & $30 \mathrm{~min}$ & $60 \mathrm{~min}$ & $120 \mathrm{~min}$ & $180 \mathrm{~min}$ & $240 \mathrm{~min}$ \\
\hline \multicolumn{7}{|l|}{ Shunt } \\
\hline $\operatorname{rhACE} 2(n=6)$ & $2.0 \pm 2.5$ & $8.4 \pm 3.4$ & $16.9 \pm 13.5$ & $12.0 \pm 8.9$ & $11.6 \pm 8.2$ & $9.3 \pm 5.1$ \\
\hline Control $(n=6)$ & $2.3 \pm 2.5$ & $14.4 \pm 13.5$ & $24.9 \pm 13.9$ & $27.3 \pm 19.3$ & $20.0 \pm 14.4$ & $11.9 \pm 9.5$ \\
\hline \multicolumn{7}{|l|}{ Low $V_{A} / Q$ of $Q$} \\
\hline $\operatorname{rhACE} 2(n=6)$ & $0.0 \pm 0.0$ & $11.4 \pm 12.4$ & $4.0 \pm 7.6$ & $4.4 \pm 9.9$ & $0.2 \pm 0.4$ & $1.4 \pm 2.2$ \\
\hline Control $(n=6)$ & $0.2 \pm 0.4$ & $22.8 \pm 18.9$ & $6.3 \pm 6.4$ & $1.8 \pm 2.7$ & $0.5 \pm 0.8$ & $10.4 \pm 12.8$ \\
\hline \multicolumn{7}{|l|}{ Norm $V_{A} / Q$ of $Q$} \\
\hline $\operatorname{rhACE} 2(n=6)$ & $98.0 \pm 2.5$ & $80.2 \pm 14.6$ & $79.0 \pm 20.9$ & $83.5 \pm 17.3$ & $88.1 \pm 8.6$ & $88.9 \pm 5.1$ \\
\hline Control $(n=6)$ & $97.5 \pm 2.4$ & $62.8 \pm 19.8$ & $68.8 \pm 13.7$ & $70.6 \pm 19.1$ & $79.5 \pm 14.4$ & $77.6 \pm 17.1$ \\
\hline \multicolumn{7}{|l|}{ Mean of $Q$} \\
\hline $\operatorname{rhACE} 2(n=6)$ & $0.46 \pm 0.21$ & $0.32 \pm 0.12$ & $0.37 \pm 0.14$ & $0.44 \pm 0.18$ & $0.44 \pm 0.14$ & $0.49 \pm 0.25$ \\
\hline Control $(n=6)$ & $0.55 \pm 0.13$ & $0.27 \pm 0.16$ & $0.38 \pm 0.11$ & $0.44 \pm 0.13$ & $0.41 \pm 0.12$ & $0.39 \pm 0.19$ \\
\hline \multicolumn{7}{|l|}{$\log \mathrm{SDQ}$} \\
\hline $\operatorname{rhACE} 2(n=6)$ & $0.34 \pm 0.08$ & $0.99 \pm 0.33$ & $0.76 \pm 0.37$ & $0.69 \pm 0.15$ & $0.60 \pm 0.11$ & $0.71 \pm 0.21$ \\
\hline Control $(n=6)$ & $0.39 \pm 0.09$ & $1.29 \pm 0.43$ & $0.88 \pm 0.37$ & $0.73 \pm 0.33$ & $0.56 \pm 0.18$ & $0.69 \pm 0.34$ \\
\hline \multicolumn{7}{|l|}{ Dead space } \\
\hline rhACE2 $(n=6)$ & $46.1 \pm 11.5$ & $45.0 \pm 9.6$ & $45.9 \pm 9.2$ & $43.0 \pm 8.9$ & $47.1 \pm 10.2$ & $45.8 \pm 11.1$ \\
\hline Control $(n=6)$ & $49.5 \pm 11.9$ & $53.5 \pm 4.4$ & $50.3 \pm 7.8$ & $50.8 \pm 5.7$ & $52.6 \pm 4.3$ & $52.1 \pm 13.8$ \\
\hline \multicolumn{7}{|l|}{$V_{A}$ (BTPS) } \\
\hline $\operatorname{rhACE} 2(n=6)$ & $3.8 \pm 0.7$ & $3.9 \pm 0.7$ & $3.9 \pm 0.7$ & $3.9 \pm 0.7$ & $4.0 \pm 0.7$ & $3.9 \pm 0.7$ \\
\hline Control $(n=6)$ & $3.4 \pm 0.6$ & $3.4 \pm 0.7$ & $3.4 \pm 0.6$ & $3.4 \pm 0.7$ & $3.3 \pm 0.7$ & $3.4 \pm 0.6$ \\
\hline
\end{tabular}

rhACE2: recombinant humane angiotensin-converting enzyme 2; shunt: unventilated lung units (\%); low $V_{A} / Q$ : lung units with a low $V_{A} / Q$ ratio (\%); norm $V_{A} / Q$ : normal $V_{A} / Q$ lung units (\%); mean of Q: mean of the distribution of perfusion; log SDQ: logarithmic standard deviation of the mean of the distribution of perfusion; dead space ventilation: lung units without blood flow (\%); $V_{A}$ (BTPS): respiratory minute volume under body conditions (L/min). Values are mean \pm SD.

$\mathrm{PaO}_{2}: \quad$ Arterial partial pressure of oxygen

$\mathrm{PaCO}_{2}$ : Arterial partial pressure of carbon dioxide

pHa: Arterial pH

CVP: $\quad$ Central venous pressure

LPS: Lipopolysaccharide

LogSDQ: Logarithmic standard deviation of perfusion distribution

MAP: $\quad$ Mean arterial pressure

MPAP: Mean pulmonary arterial pressure

$\mathrm{PvCO}_{2}$ : Mixed venous partial pressure of carbon dioxide

$\mathrm{PvO}_{2}$ : $\quad$ Mixed venous partial pressure of oxygen

MIGET: Multiple inert gas elimination technique

PCWP: Pulmonary capillary wedge pressure

PVR: Pulmonary vascular resistance

$V_{A} / Q: \quad$ Ventilation/perfusion ratio.

\section{Conflict of Interests}

No author has declared conflict of interests. However, Ralf Geiger has received an unrestricted grant and reimbursement for travel expenses from Actelion Pharmaceuticals Ltd. as well as an unrestricted grant from Bayer Pharma AG.

\section{Acknowledgments}

This work was supported by a grant of the "Österreichische Forschungsförderungsgesellschaft mbH” (Project no.
$812112 / 11157-S C K / K U G)$. The authors would like to thank Manfred Schuster (Apeiron Biologics AG, Vienna, Austria) for preparation of ACE2 and measurements of Ang II and ACE2 activity. They would like to thank Dr. Sergi Consolato and Dr. Nadezda Gut for scoring the histologic lung tissue sections.

\section{References}

[1] L. B. Ware and M. A. Matthay, "The acute respiratory distress syndrome," The New England Journal of Medicine, vol. 342, no. 18, pp. 1334-1349, 2000.

[2] T. E. Wiswell and R. C. Bent, "Meconium staining and the meconium aspiration syndrome: unresolved issues," Pediatric Clinics of North America, vol. 40, no. 5, pp. 955-981, 1993.

[3] G. M. Cleary and T. E. Wiswell, "Meconium-stained amniotic fluid and the meconium aspiration syndrome: an update," Pediatric Clinics of North America, vol. 45, no. 3, pp. 511-529, 1998.

[4] M. Donoghue, F. Hsieh, E. Baronas et al., "A novel angiotensinconverting enzyme-related carboxypeptidase (ACE2) converts angiotensin I to angiotensin 1-9," Circulation research, vol. 87, no. 5, pp. E1-E9, 2000.

[5] C. Vickers, P. Hales, V. Kaushik et al., "Hydrolysis of biological peptides by human angiotensin-converting enzyme-related carboxypeptidase," The Journal of Biological Chemistry, vol. 277, no. 17, pp. 14838-14843, 2002.

[6] S. R. Tipnis, N. M. Hooper, R. Hyde, E. Karran, G. Christie, and A. J. Turner, "A human homolog of angiotensin-converting 
enzyme: cloning and functional expression as a captoprilinsensitive carboxypeptidase," The Journal of Biological Chemistry, vol. 275, no. 43, pp. 33238-33243, 2000.

[7] Y. Imai, K. Kuba, S. Rao et al., "Angiotensin-converting enzyme 2 protects from severe acute lung failure," Nature, vol. 436, no. 7047, pp. 112-116, 2005.

[8] B. Treml, N. Neu, A. Kleinsasser et al., "Recombinant angiotensin-converting enzyme 2 improves pulmonary blood flow and oxygenation in lipopolysaccharide-induced lung injury in piglets," Critical Care Medicine, vol. 38, no. 2, pp. 596601, 2010.

[9] P. D. Wagner, H. A. Saltzman, and J. B. West, "Measurement of continuous distributions of ventilation perfusion ratios: theory," Journal of Applied Physiology, vol. 36, no. 5, pp. 588-599, 1974.

[10] P. D. Wagner, P. F. Naumann, and R. B. Laravuso, "Simultaneous measurement of eight foreign gases in blood by gas chromatography," Journal of Applied Physiology, vol. 36, no. 5, pp. 600-605, 1974.

[11] L. E. Farhi and A. J. Olszowka, "Analysis of alveolar gas exchange in the presence of soluble inert gases," Respiration Physiology, vol. 5, no. 1, pp. 53-67, 1968.

[12] D. Vidyasagar and A. Zagariya, "Studies of meconium-induced lung injury: inflammatory cytokine expression and apoptosis," Journal of Perinatology, vol. 28, supplement 3, pp. S102-S107, 2008.

[13] L. T. Skeggs, F. E. Dorer, M. Levine, K. E. Lentz, and J. R. Kahn, "The biochemistry of the renin-angiotensin system," Advances in Experimental Medicine and Biology, vol. 130, pp. 1-27, 1980.

[14] S. Idell, F. Kueppers, M. Lippmann, H. Rosen, M. Niederman, and A. Fein, "Angiotensin converting enzyme in bronchoalveolar lavage in ARDS," Chest, vol. 91, no. 1, pp. 52-56, 1987.

[15] C. R. Rosenfeld, A. M. Zagariya, X. T. Liu, B. C. Willis, S. Fluharty, and D. Vidyasagar, "Meconium increases type 1 angiotensin II receptor expression and alveolar cell death," Pediatric Research, vol. 63, no. 3, pp. 251-256, 2008.

[16] N. Klein, F. Gembardt, S. Supé et al., "Angiotensin-(1-7) protects from experimental acute lung injury," Critical Care Medicine, vol. 41, no. 11, pp. e334-e343, 2013.

[17] Q. Chen, Y. Yang, Y. Huang, C. Pan, L. Liu, and H. Qiu, "Angiotensin-(1-7) attenuates lung fibrosis by way of Mas receptor in acute lung injury," Journal of Surgical Research, vol. 185, no. 2, pp. 740-747, 2013.

[18] X. He, B. Han, M. Mura et al., "Angiotensin-converting enzyme inhibitor captopril prevents oleic acid-induced severe acute lung injury in rats," Shock, vol. 28, no. 1, pp. 106-111, 2007.

[19] H.-M. Liu and Y.-N. Guo, "Effect of captopril on serum TNF- $\alpha$ level in acute lung injury rats induced by HCL," Asian Pacific Journal of Tropical Medicine, vol. 7, no. 11, pp. 905-908, 2014. 


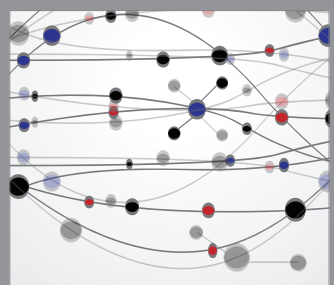

The Scientific World Journal
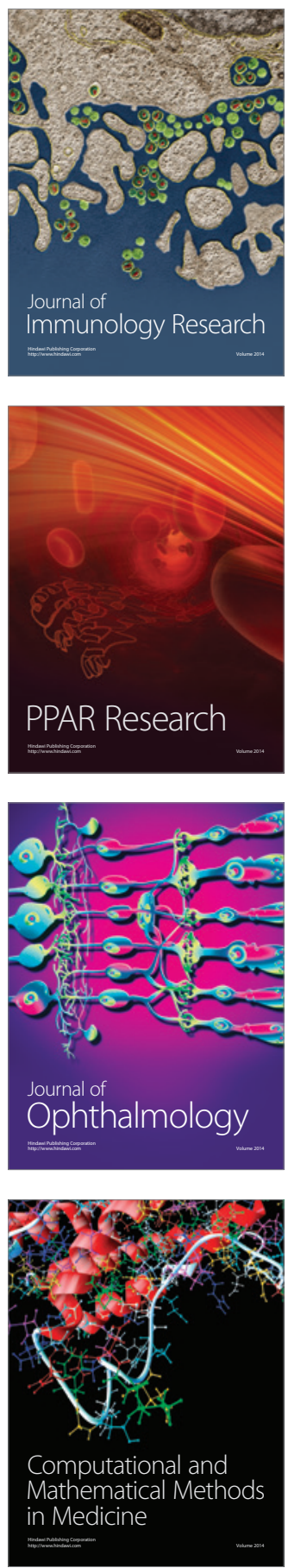

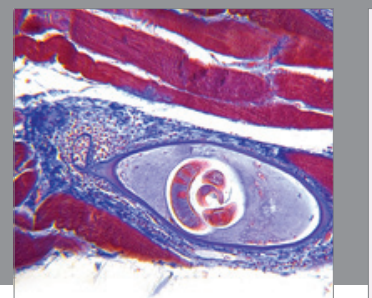

Gastroenterology

Research and Practice
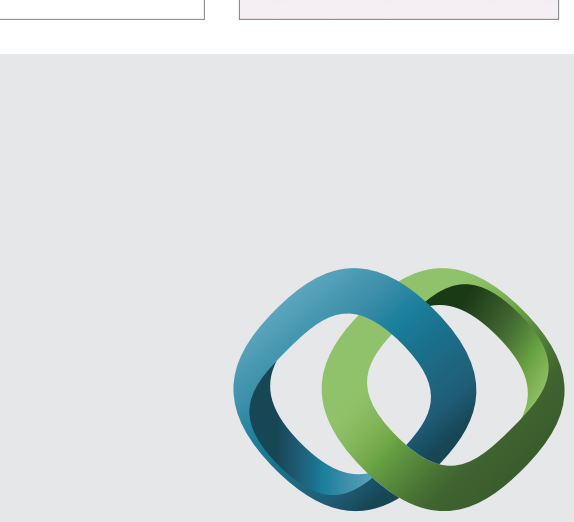

\section{Hindawi}

Submit your manuscripts at

http://www.hindawi.com
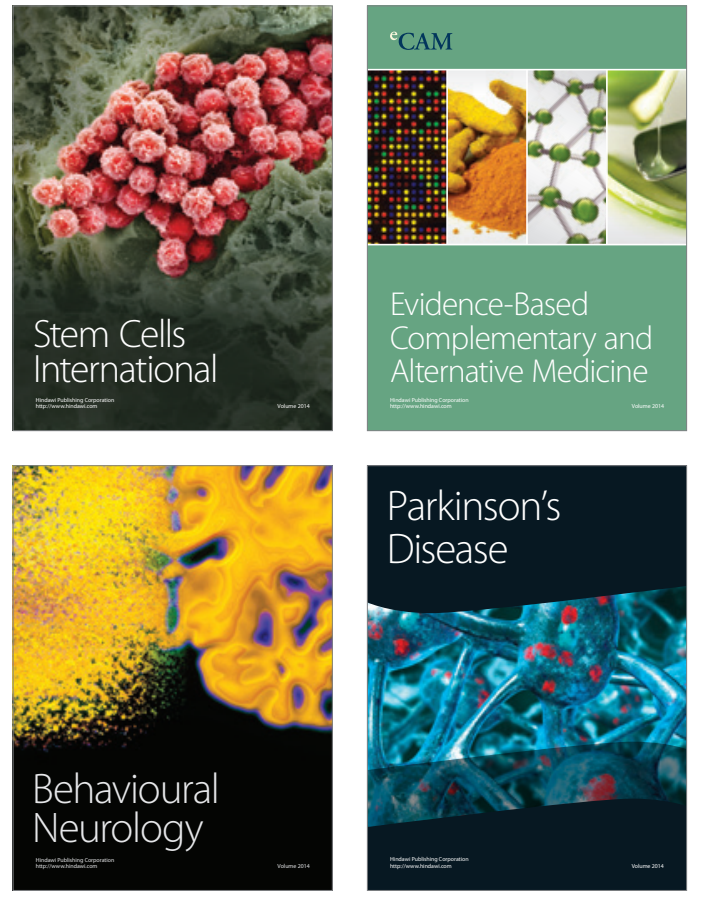
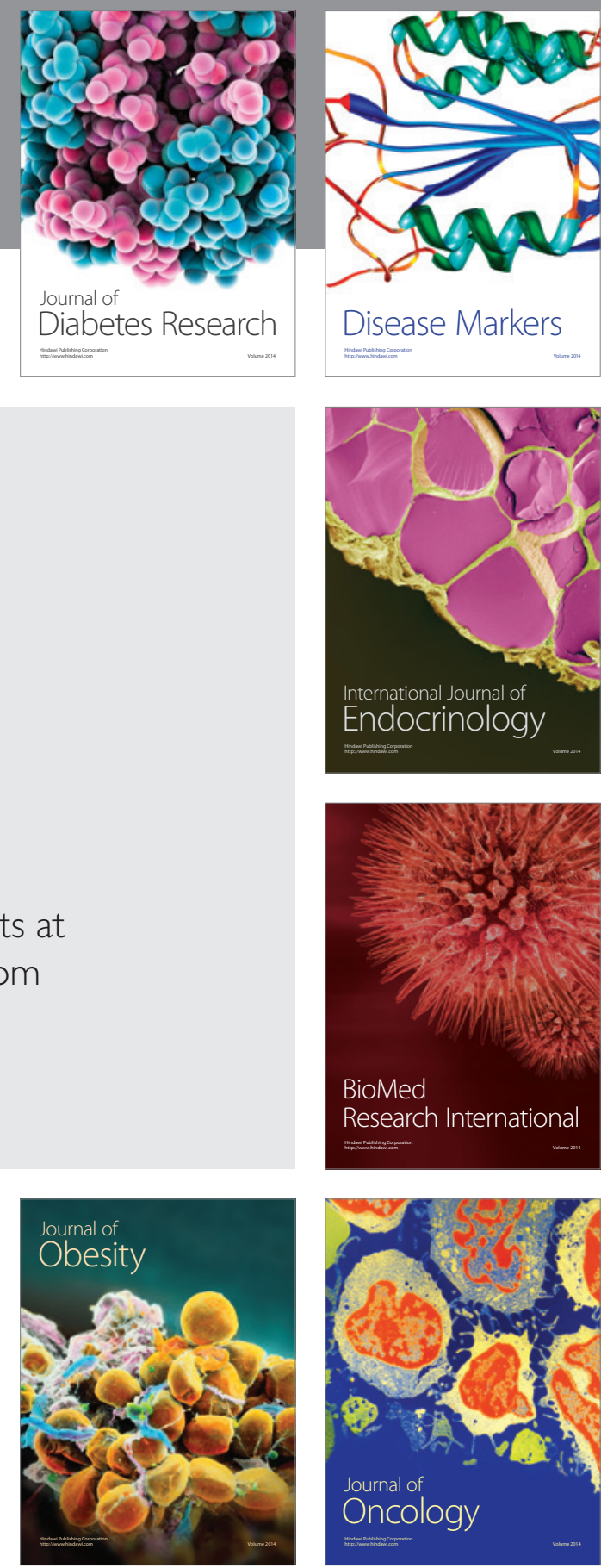

Disease Markers
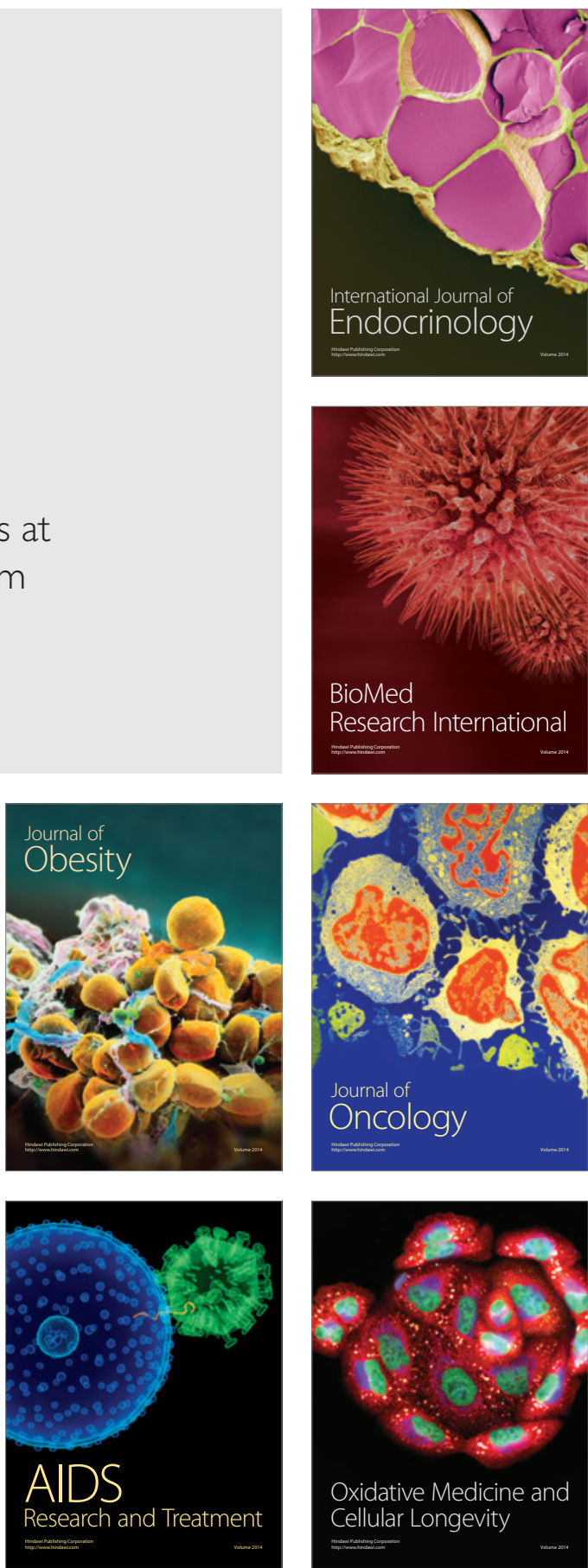